\title{
De parque a APA: uma análise do processo de recategorização de parte do Parque Estadual da Serra do Tabuleiro-SC ${ }^{1}$
}

\begin{abstract}
Resumo
O Parque Estadual da Serra do Tabuleiro (PEST) é a maior Unidade de Conservação do estado de Santa Catarina com um território que corresponde aproximadamente a um por cento do estado. Criado em 1975, vem desde então sendo motivo de conflitos entre a população, que se sente prejudica pela criação do parque, e o poder público. Este artigo analisa o processo que iniciou em $2004 \mathrm{e}$ resultou, em 2009, na mudança de categoria de unidade de conservação de partes do Parque. A análise desse processo tem foco na Baixada do Maciambú, no município de Palhoça, que passou da categoria de Parque à de Área de Preservação Ambiental (APA). Como fontes, foram utilizados principalmente periódicos, folhetos explicativos voltados aos moradores e legislação. A análise do processo de recategorização da Baixada do Maciambú se deu a partir de pressupostos teórico-metodológicos da História Ambiental na medida em que se percebe o papel do meio ambiente e sua influência na vida humana e vice-versa, bem como sua representação e percepção. Como resultado, tem-se que o projeto de recategorização não foi aceito de maneira unânime entre os sujeitos envolvidos e, por isso, gerou conflitos entre aqueles que eram a favor e os que eram contra a recategorização. Além disso, mesmo definido em lei em 2009, os esforços despendidos nesse projeto correm o risco de serem anulados a partir do entendimento da Procuradoria Geral da República que, em 2015, entrou com Ação Direta de Inconstitucionalidade contra a lei que alterou a UC, o que dá à temática um caráter ainda mais atual e relevante.
\end{abstract}

Palavras-chave: Parque Estadual da Serra do Tabuleiro. Unidades de Conservação. Baixada do Maciambú. Recategorização.

\author{
Jackson Alexsandro Peres \\ Doutor em História Cultural pela \\ Universidade Federal de Santa Catarina \\ (UFSC). Professor da Faculdade \\ Municipal de Palhoça (FMP). \\ Palhoça - SC - BRASIL \\ jackson.peres@fmpsc.edu.br \\ orcid.org/0000-0003-0799-395X
}

\section{Para citar este artigo:}

PERES, Jackson Alexsandro. De parque a APA: uma análise do processo de recategorização de parte do Parque Estadual da Serra do Tabuleiro-SC. Tempo e Argumento, Florianópolis, v. 11, n. 26, p. 114 - 134, jan./abr. 2019.

\section{DOI: $\mathbf{1 0 . 5 9 6 5 / 2 1 7 5 1 8 0 3 1 1 2 6 2 0 1 9 1 1 4}$}

http://dx.doi.org/10.5965/2175180311262019114

\footnotetext{
1 O presente texto é uma versão modificada de parte da Tese intitulada Parque Estadual da Serra do Tabuleiro: natureza, legislação e conflitos na Baixada do Maciambú - Palhoça/SC (1975-2012), defendida no programa de Programa de Pós-Graduação em História da UFSC em 2017 e orientada pela Profa. Dra . Eunice Sueli Nodari.
} 


\title{
From park to APA: an analysis of
}

\section{the recategorization process of part of the State Park of Serra do}

\section{Tabuleiro-SC}

\begin{abstract}
The Serra do Tabuleiro State Park (PEST) is the largest Conservation Unit in the State of Santa Catarina with a territory that corresponds to approximately one percent of the State. Created in 1975, it has since been the subject of conflicts between the population that feels disadvantaged by the creation of the park and the public power. This article analyzes the process that began in 2004 and resulted in 2009 in the change of category of conservation unit of parts of the Park. The analysis of this process focuses on the Baixada do Maciambú, in the municipality of Palhoça, which changed from the category of park to the category of Environmental Preservation Area (APA). As sources, mainly periodicals, leaflets explaining to the residents and legislation were used. The analysis of the process of recategorization of the Baixada do Maciambú was based on the theoretical and methodological assumptions of Environmental History, insofar as one can perceive the role of the environment and its influence on human life and vice versa, as well as its representation and perception . As a result, it has been that the recategorization project was not unanimous among the subjects involved and therefore generated conflicts between those who were in favor and those who were against recategorization. In addition, even defined in law in 2009, the efforts expended in this project run the risk of being annulled from the understanding of the Attorney General's Office that in 2015 filed a Direct Unconstitutionality Action against the law that changed the UC, which gives to the theme an even more current and relevant character.
\end{abstract}

Keywords: Serra do Tabuleiro State Park. Conservation Units. Baixada do Maciambú. Recategorization.

\section{Introdução}

A chegada dos europeus no território que hoje compreende o Brasil fez crescer rapidamente a pressão humana sobre o ambiente natural. Até o século XVIII, essa pressão se deu principalmente de norte ao sul nas áreas próximas ao litoral, áreas de abrangência 
do Bioma Mata Atlântica². Com o ambiente natural sendo gradativamente degradado, passou-se a pensar em maneiras de pelo menos controlar a exploração dos recursos naturais. Ainda no período colonial, surgiram as primeiras manifestações por parte da Coroa Portuguesa em preservar as matas, principalmente aquelas que costeavam os rios e permitiam que os portugueses estocassem madeira sem precisar adentrar as florestas. Uma carta régia de D. Maria I ao Governador da Capitania de Pernambuco determinava punição severa aos que incendiassem ou destruíssem as matas (MORETTO; CARVALHO; NODARI, 2010). Porém, segundo José Augusto Pádua (2004), somente a partir do final do século XVIII pode-se observar no Brasil uma reflexão profunda e consistente sobre o problema da destruição do ambiente natural.

As reflexões sobre $\mathrm{o}$ ambiente natural e sua relação com 0 humano desencadearam alguns avanços, como a recuperação da Floresta da Tijuca, no Rio de Janeiro, e a transformação do Museu Nacional, do Jardim Botânico e do Instituto de Manguinhos (hoje Fundação Oswaldo Cruz) como importantes centros de pesquisas. "Esse interesse científico pela natureza coincidiu com o surgimento de preocupações com a proteção do patrimônio natural brasileiro, com base em argumentos tanto de utilidade econômica quanto de fruição estética" (FRANCO; DRUMMOND, 2012, p. 336). Dessas preocupações e interesses surgiram as leis que passaram a tratar da temática. 0 primeiro Código Florestal Brasileiro foi regulamentado em 1934, prevendo áreas que seriam protegidas por meio de criação de Parques. O primeiro Parque Nacional criado a partir da lei de 1934 foi o Parque Nacional do Itatiaia, no estado do Rio de Janeiro (DEAN, 1996; FRANCO; DRUMMOND, 2012). Em 1965, o país teve seu novo Código Florestal, em um período especialmente marcante ${ }^{3}$ para as discussões a respeito do Meio Ambiente. No contexto e dentro da legislação vigente do Código Florestal de 1965, foi criado o Parque Estadual da Serra do Tabuleiro (PEST), no estado de Santa Catarina.

\footnotetext{
2Bioma é um conjunto de vida (vegetal e animal) constituído pelo agrupamento de tipos de vegetação contíguos e identificáveis em escala regional, com condições geoclimáticas similares e história compartilhada de mudanças, o que resulta em uma diversidade biológica própria (IBGE, 2015).

3 Especialmente marcante pelo fato de ser observada, durante as décadas de 1960 e 1970, uma série de acontecimentos importantes em relação ao Meio Ambiente, como por exemplo: publicação, em 1962, da obra "Primavera silenciosa" de Rachel Carson; a fundação do Green Peace em 1971; a publicação do "Relatório Meadows" (Os limites do Crescimento) em 1972 (mesmo ano em que ocorreu a Conferência das Nações Unidas sobre o Meio Ambiente); e o surgimento do Partido da Ecologia (EcologyParty) na Inglaterra em 1973.
} 
O Parque Estadual da Serra do Tabuleiro foi criado pelo Decreto do Estado de Santa Catarina n. 1.260, de novembro de 1975. Sua criação se deu a partir de esforços de diferentes sujeitos que enxergavam na área características ambientais que precisavam ser preservadas. O PEST ocupa cerca de um por cento do território do estado de Santa Catarina e se distribui por oito municípios: Florianópolis, Palhoça, Santo Amaro da Imperatriz, Águas Mornas, São Bonifácio, Imaruí, São Martinho e Paulo Lopes (figura 1). Durante os mais de 40 anos desde a sua criação, os limites de seu território se alteraram diversas vezes por meio de decretos governamentais que levaram em conta estudos técnicos e a viabilidade da implantação plena desta UC.

Figura 1: Parque Estadual da Serra do Tabuleiro em 2009

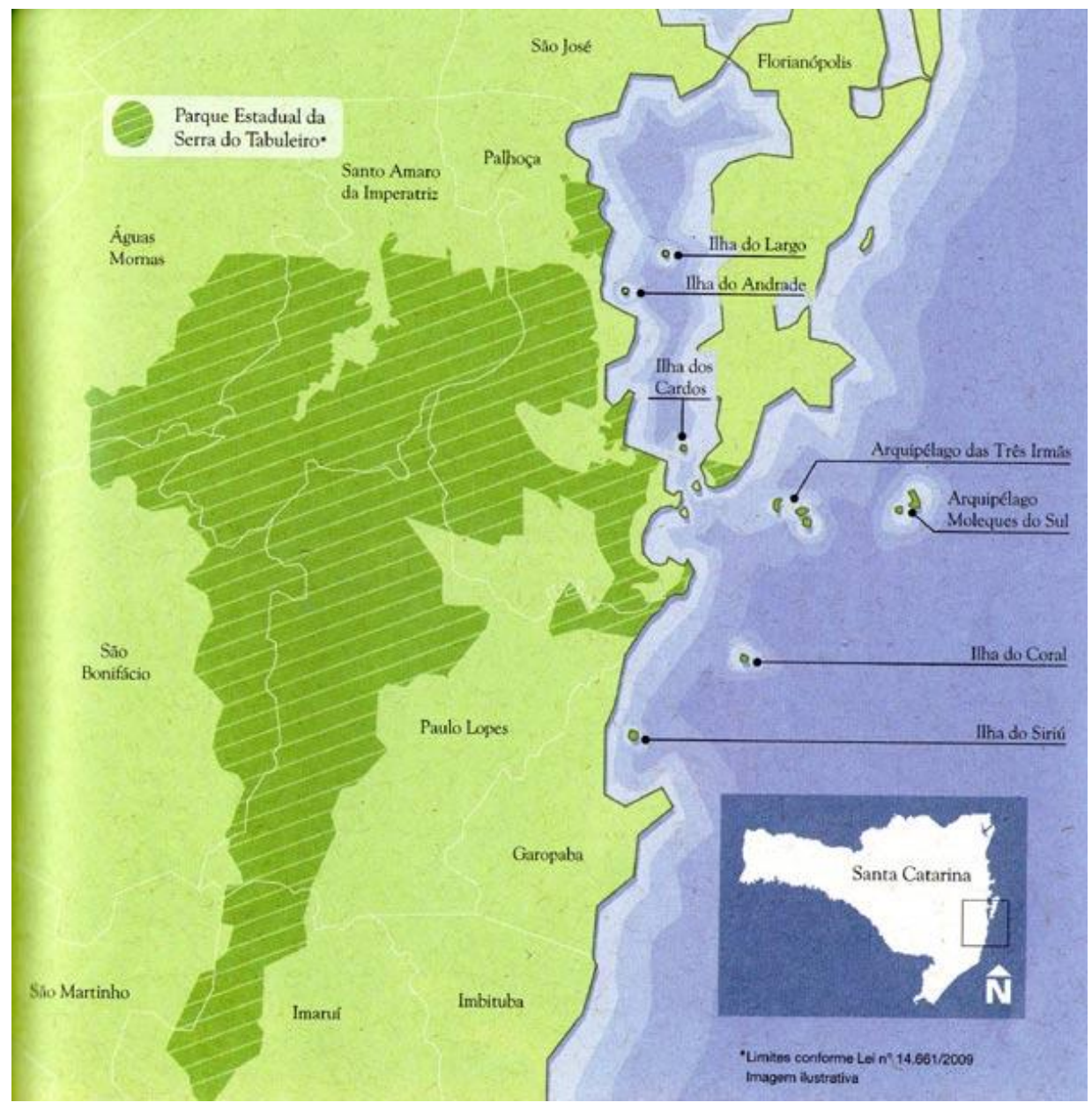

Fonte: FATMA, 2009, p. 23.

Sem indenizações e, muitas vezes, sem informações sobre a real situação em que se encontravam, os moradores de algumas localidades que passaram a integrar a UC 
começaram a ter problemas no desenvolvimento de suas atividades ${ }^{4}$. Um dos locais em que esses problemas se evidenciaram foi em parte da região sul do município de Palhoça, conhecida como Baixada do Maciambú. Isso porque no local encontrava-se uma população que não teve parte nas discussões de implantação do parque nem tampouco teve informações sobre como ficaria sua situação. A área da Baixada do Maciambú está localizada entre os rios Maciambú e da Madre (figura 2), no sul do município de Palhoça SC, na região da Grande Florianópolis, sendo que o rio da Madre é o limite entre os municípios de Palhoça e Paulo Lopes. Na Baixada do Maciambú estão localizados os bairros: Passagem do Maciambú, Praia do Sonho, Ponta do Papagaio, Pinheira e Guarda do Embaú, área litorânea de grande importância econômica para o município por conta do apelo turístico. Ressalta-se que Palhoça, a partir de 1975, teve 54\% de seu território transformado em Parque (PEST), contribuindo assim, com 19\% do território total do PEST.

Figura 2: Baixada do Maciambú

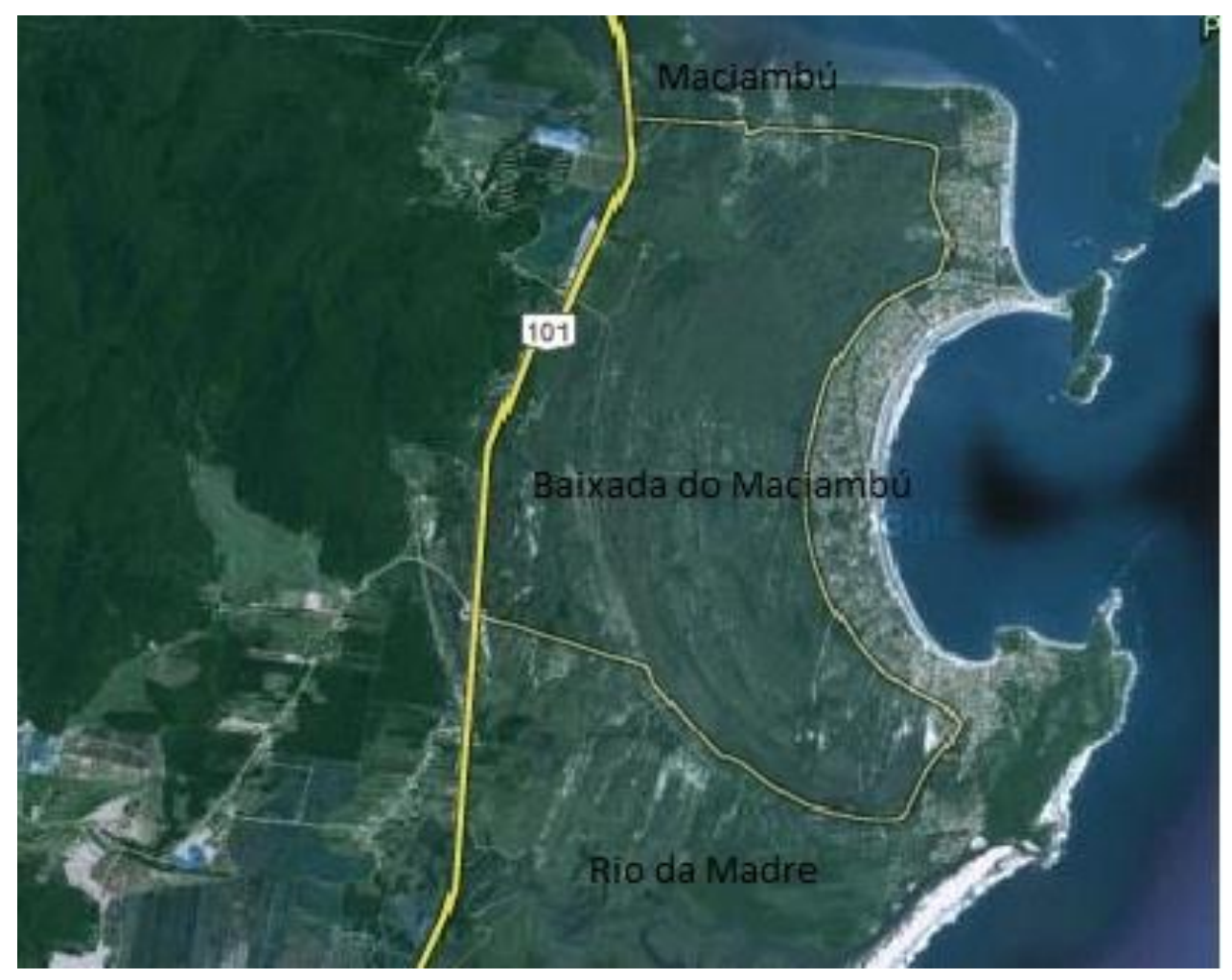

Fonte: www.googlemaps.com. Imagem adaptada.

\footnotetext{
4 Cristiane Fortkamp pesquisou como o Parque Estadual da Serra do Tabuleiro entrou na vida dos moradores, principalmente dos municípios de São Bonifácio e Santo Amaro da Imperatriz, que se encontram no início da região serrana de Santa Catarina e que possuem partes de seus territórios dentro dos limites doPEST. A pesquisa se deu em nível de mestrado e recomenda-se sua leitura, já que a autora identifica os conflitos socioambientais decorrentes do processo da instalação do Parque nessa região.
} 
Para dar agilidade à implantação do Parque, seu território foi modificado. A área da Baixada do Maciambú, que em 1975 fazia parte do Parque, foi desanexada pelo Decreto n. 8.857, de 07 de setembro de 1979. Ocorre que mesmo sendo desanexada, a área ainda estava sob a administração da Fundação do Meio Ambiente (FATMA), e por ser uma área do entorno do Parque, a exploração obedecia a uma legislação específica.

Os problemas se tornaram frequentes e se intensificaram durante a década de 1990. Mobilizados em obter soluções para os conflitos que desde 1975 vinham ocorrendo na Baixada do Maciambú, mesmo estando essa área fora da UC desde 1979, a sociedade civil organizada passou a negociar com o poder público na tentativa de equacionar o desenvolvimento da região, com o acesso da população à infraestrutura e qualidade de vida aliadas à preservação ambiental, da qual a economia da região depende diretamente. Dessa mobilização resultou a última mudança em relação ao PEST, quando se conseguiu aprovar na Assembleia Legislativa do Estado de Santa Catarina o Projeto de Recategorização do Parque Estadual da Serra do Tabuleiro, o que ocorreu em 2009.

\section{Recategorização: solução para os problemas da Baixada do Maciambú?}

A década de 1990 e o início dos anos 2000 se tornaram um divisor de águas para o PEST. Isso porque com o aumento populacional da Baixada do Maciambú, a especulação imobiliária e o aumento do turismo, a pressão sobre o meio ambiente e problemas de cunho jurídico na venda de terrenos, alardeou os órgãos responsáveis pela administração do parque aumentando também os conflitos socioambientais na região.

Em 2005 cresce a tendência a uma recategorização do Parque, que previa a mudança de categoria da área costeira e entorno para Área de Proteção Ambiental (APA), de modo que foi criado o Fórum Parlamentar Permanente para discutir as propostas.

O movimento pela recategorização nasceu em novembro de 2004 em uma reunião com as associações comunitárias, liderada pela Associação dos Defensores do Balneário Ponta do Papagaio. Segundo notícia veiculada no Jornal Espinheira5,

\footnotetext{
5 Jornal local que circulou entre 1994 e 2007. Periodicidade mensal.
} 
Mudar de categoria de Parque Estadual para Área de Proteção Ambiental (APA) é o que pretende uma comissão criada pela Associação dos Defensores do Balneário Ponta do Papagaio, em relação à região litorânea do Parque Estadual da Serra do Tabuleiro, área que abrange parte dos municípios de Garopaba, Paulo Lopes e Palhoça e tem como divisor a BR-101. (ESPINHEIRA, 2005, p. 2)

A mudança foi defendida pela comissão por conta da legislação que rege as duas categorias de UC. Enquanto a categoria "parque" é considerada uma Unidade de Proteção Integral, não permitindo a ocupação humana, a APA (Área de Proteção Ambiental) é uma unidade de uso sustentável, que permite a ocupação humana disciplinada. A proposta foi levada à comunidade por meio de reuniões em diferentes localidades e apresentada como solução para os impasses que as restrições causavam aos moradores da região.

Em maio de 2005, a comissão levou a ideia do projeto à Assembleia Legislativa de Santa Catarina (ALESC) e ao então Governador Luiz Henrique da Silveira. "Com sinal verde do governador e apoio de 50 empresários e várias associações dos três municípios, foi iniciada a elaboração do projeto" (ESPINHEIRA, 2005, p. 2).

A partir da deflagração do movimento, iniciou-se um embate ideológico entre os que criaram a comissão e defendiam o projeto e aqueles que consideravam o projeto inviável e que acarretaria em prejuízo tanto para o Meio Ambiente quanto para a sociedade. Esses embates se davam em reuniões e por meio dos periódicos locais, que passaram a documentar os passos de todo o processo.

Órgãos como a FATMA e até a equipe técnica do Centro de Visitantes do PEST se posicionaram em relação ao projeto, esclarecendo todos os aspectos que gerariam essa mudança para facilitar o entendimento dos interessados. No Jornal Espinheira, de janeiro de 2006, os dois órgãos se manifestaram a respeito do assunto que ainda estava em fase de elaboração. O intuito era deixar as informações mais claras para que a população, que não acompanhava diretamente o processo, pudesse formar sua opinião sobre o projeto, que já nascera polêmico. Os órgãos responderam as questões mais pontuais sobre a problemática em questão. A figura a seguir, retirada do periódico, foi publicada pelo Centro de Visitantes, para didaticamente explicar o que significaria a mudança, caso fosse aprovada: 
Figura 3: Representação da Baixada do Maciambú de acordo com a proposta de Recategorização

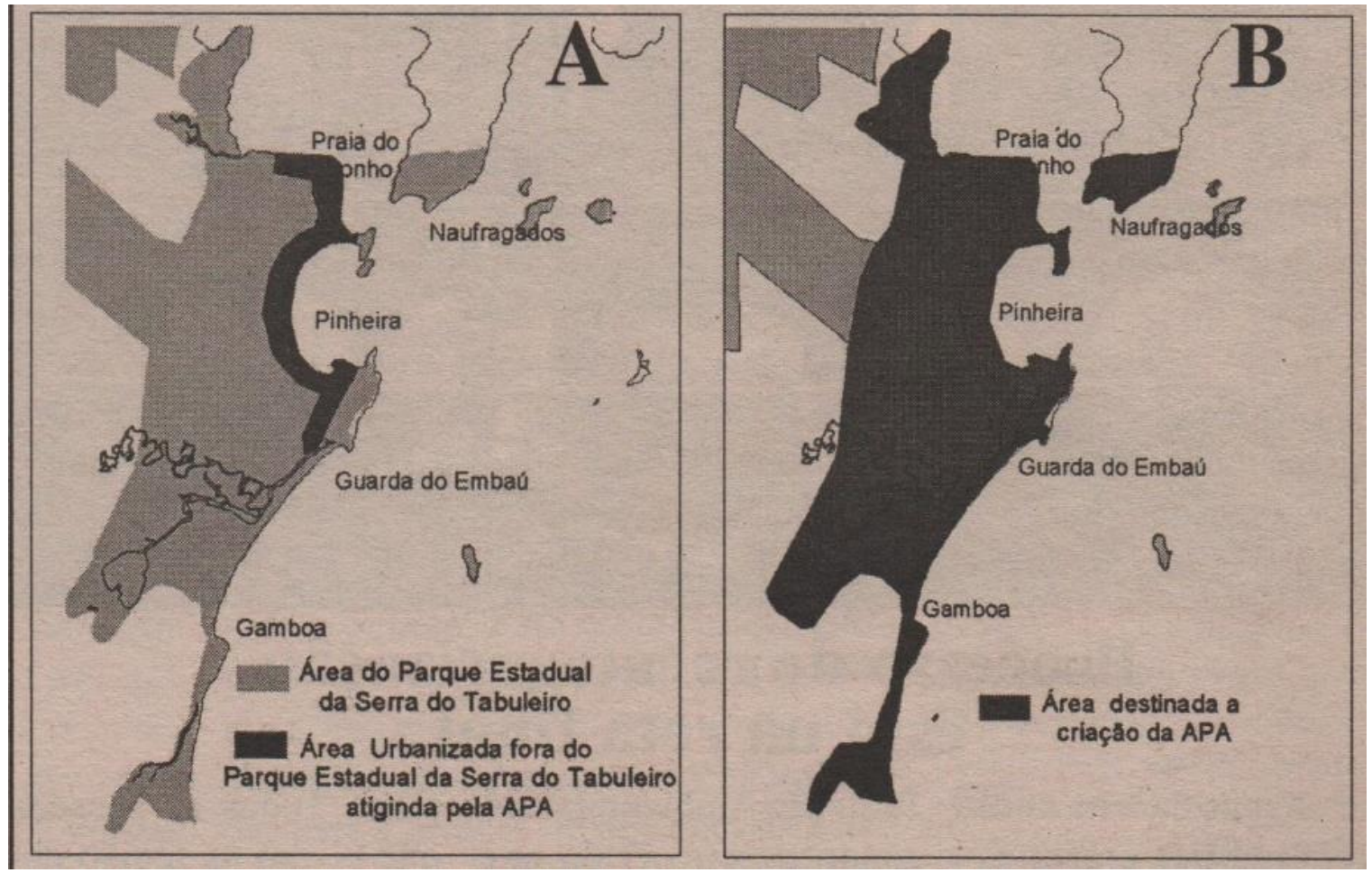

Fonte: ESPINHEIRA, 2006, p. 4.

Os técnicos do Centro de Visitantes explicam por meio dos mapas a questão. A letra A representa a situação da área em 2005 e a B, como ficaria o local com a recategorização. Moradores que estariam fora do Parque (Mapa A) ficariam dentro de uma APA (mapa B). Com isso, haveria aumento das restrições ambientais para seus terrenos. O aumento seria sentido nas comunidades da Guarda do Embaú, Pinheira, Praia do Sonho e Passagem do Maciambú, que estavam fora do Parque desde 1979. De qualquer forma, essas localidades já tinham restrições por estarem em região do entorno e por conta de legislações específicas que regulavam as particularidades do local. Ainda segundo os técnicos, as APA são áreas protegidas que recebem menos investimentos no país (ESPINHEIRA, 2006, p. 4).

Ao encontro dessas informações, a Diretora de Proteção dos Ecossistemas da FATMA no período, Ana Cimardi, em entrevista ao jornal Espinheira, informou que com a criação da APA, as restrições baseadas em leis federais e estaduais não deixariam de existir. Além disso, toda a região que já estava fora de uma UC passaria novamente a integrá-la. Para Ana Cimardi, as restrições impostas pelo fato de a área estar na zona do 
entorno, o que configuraria em uma Área de Proteção Especial (APE), seriam um fator fácil de resolver. Outra questão levantada por Cimardi é que, como a APA englobaria quatro municípios, necessariamente estaria sob a administração estadual. Portanto, a FATMA seria a administradora dessa UC conforme rege o SNUC, de modo que mesmo que se firmassem termos de parceria para implantar uma gestão compartilhada com organizações não governamentais, a FATMA seria a principal gestora da UC (ESPINHEIRA, 2006, p.5).

Alheios aos questionamentos feitos pelos órgãos competentes, os idealizadores do projeto seguiram com a proposta a passos largos, sendo que em fevereiro de 2006 "a parte técnica do projeto de lei para recategorização da região costeira do Parque do Tabuleiro e seu entorno já está concluída" (ESPINHEIRA, 2006, p. 3). O passo a seguir seria a entrega do projeto de lei ao governador para que ele o repassasse à ALESC. Pretendia-se que a lei fosse votada até março.

Em abril do mesmo ano, a FATMA considerou a proposta inviável e insistiu nas ações que já estavam sendo empreendidas para amenizar a situação que se arrastava desde 1975. A principal delas seria a extinção das Áreas de Preservação Especial (APE) ou de entorno através de alteração no Decreto Estadual n. 14.250/81. Desse modo, a área que já estava desanexada também não faria mais parte do entorno do Parque, diminuindo assim as restrições impostas (ESPINHEIRA, 2006, p.3).

Para acalmar os ânimos e ampliar o debate acerca do assunto, foi criado pela ALESC, em 4 de abril de 2006, o Fórum Parlamentar de Debate sobre o Parque e seu Entorno, reunindo todos os envolvidos na questão. O objetivo foi criar um grupo técnico para avaliar as propostas existentes, confrontando-as e buscando alternativas para a resolução dos conflitos. No grupo estavam representantes do movimento de recategorização, representantes da Entidade de Ecologistas Catarinenses, da Associação da Praia de Naufragados, da ALESC e da Procuradoria Geral do Estado (ESPINHEIRA, 2006, p.3). O grupo passou a se reunir para elaborar a conclusão dos estudos, que teve como resultado a elaboração de um documento no qual são apresentados sete problemas principais e sete propostas para a resolução desses problemas. Os principais impasses dizem respeito a questões fundiárias da área da Baixada do Maciambú no 
entorno do Parque, à falta de demarcação física consolidada dos limites do Parque e à inexistência do plano de manejo da UC. Em contrapartida, o movimento de recategorização se comprometeu em interromper os trabalhos de promoção da ideia e retirar definitivamente a proposta logo que os compromissos assumidos pela FATMA fossem concluídos (ESPINHEIRA, 2006, p.3).

Uma das propostas do Fórum ganhou corpo e saiu do papel em setembro do mesmo ano. Por meio de um decreto, o Governo do Estado revogou os artigos do Decreto n. 14.250/81 que regulamenta dispositivos da Lei n. 5.793, de 15 de outubro de 1980, referentes à Proteção e à Melhoria da Qualidade Ambiental, que instituía como Área de Proteção Especial uma faixa de 500 metros no entorno de Unidades de Conservação. De acordo com o periódico local,

Com a extinção da APE, muitos casos de ocupação poderão ser solucionados, pois uma série de restrições deixarão de existir. Ainda falta o governo repassar a titularidade da terra aos proprietários na região do

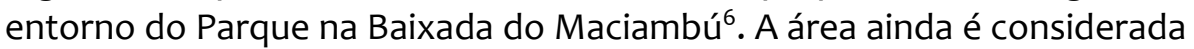
do Estado. (ESPINHEIRA, 2006, p. 3)

Em meio aos debates, continuavam os trabalhos da empresa STCP Engenharia e Projetos LTDA., que executava o projeto de delimitação e demarcação do Parque. 0 relatório sobre a delimitação e o planejamento da demarcação do Parque foram apresentados em reunião do Grupo de Trabalho do Fórum do Tabuleiro no dia 28 de outubro de 2007. Faltava a apresentação do relatório técnico e jurídico para a questão fundiária, o diagnóstico socioeconômico e a proposta de delimitação. Com base nesses documentos, novas reuniões foram marcadas para se tentar concluir os trabalhos até o final de 2007, o que aconteceria apenas em 2008. O entrave maior ainda estava na questão fundiária que causava insegurança aos moradores. O relatório apontou como alternativas de solução aos moradores de áreas fora do Parque:

\footnotetext{
${ }^{6}$ Para melhor entendimento do processo de ocupação humana na Baixada do Maciambú, ver PERES, Jackson Alexsandro. Do Porto dos Patos à Baixada do Maciambú. In: PERES, Jackson Alexsandro Peres. Parque Estadual da Serra do Tabuleiro: natureza, legislação e conflitos na Baixada do Maciambú Palhoça/SC (1975-2012).Tese. Florianópolis, UFSC, 2017.
} 
1. Legalização dos títulos vendidos pela prefeitura, pois tiraria da ilegalidade seus atuais moradores;

2. Decretação da nulidade dos títulos vendidos pela prefeitura - os imóveis voltariam a pertencer ao Estado;

3. Doação de parte da área do entorno junto ao mar para a prefeitura. (ESPINHEIRA, 2007, p. 3)

Em março de 2008 o resultado final do projeto elaborado pela STCP é apresentado. O Jornal da Recategorização, um informativo do Movimento de Recategorização do Parque Estadual da Serra do Tabuleiro (11/02/2009), apresenta um histórico de todo o processo do projeto de transformar a Baixada do Maciambú em APA, em um projeto que ficou conhecido como Mosaico, já que na região estavam previstas diferentes categorias de unidades de conservação. O documento informa que o trabalho apresentado pela empresa STCP não foi aceito pelas lideranças do movimento, prefeitos e lideranças políticas da região, mas que o grupo I continuou o projeto de recategorização. Em junho de 2008, o projeto ficou pronto e foi apresentado para a FATMA, Secretaria de Desenvolvimento Sustentável, Procuradoria Geral do Estado, Promotoria Pública do PEST, Fórum Parlamentar e comunidade.

O documento citado é composto por 16 páginas sobre o projeto de recategorização e foi distribuído gratuitamente nas ruas da região da Baixada do Maciambú, justamente na época em que o projeto seria votado na ALESC. Dado o avançado estado das discussões, a FATMA, que se posicionou contra o projeto, enviou ao Governador Luiz Henrique da Silveira um documento denominado "Recomendações da FATMA sobre o processo de reavaliação do Parque Estadual da Serra do Tabuleiro". As lideranças envolvidas no projeto repudiaram a atitude do órgão e enviaram um abaixoassinado ao Governador solicitando que se mantivesse o regime de urgência do Projeto de Lei n. $347 / 08$ (JORNAL DA RECATEGORIZAÇÃO, 2009).

Circulou, no mesmo período do documento acima, uma publicação contrária ao projeto. Intitulada "Solução sim! Pressa não!", a publicação discutia, entre outras coisas, a legalidade do projeto. Em tom de denúncia, questionava sobre os interesses por detrás do projeto, que beneficiaria uma pequena parcela de empresários e que acabaria inferindo em mais restrições aos moradores. Além do parecer negativo da FATMA, o 
Ministério Público de Santa Catarina afirmou que o Projeto Mosaico feria a Constituição em vários pontos.

A queda de braço chegou a ALESC em 2009. Em 11 de fevereiro, moradores da região do PEST foram às galerias da Assembleia pedir mais tempo para a discussão em torno do Projeto de Lei. Do mesmo modo, em 17 de fevereiro de 2009, centenas de pessoas estiveram na ALESC para também pedir aos deputados a aprovação do projeto de lei da reclassificação do Parque Estadual da Serra do Tabuleiro. O fato é que a queda de braço foi vencida por aqueles que apostavam na aprovação do projeto de recategorização da região da Baixada do Maciambú. Assim, parte do Parque foi transformada em um Mosaico de Áreas de Proteção Ambiental. Para Machado (2014, p. 135),

A Lei n. 14.661/2009 que redefiniu os limites do Parque Estadual da Serra do Tabuleiro se deu aos inúmeros conflitos existentes no Parque. Através dessa Lei, algumas áreas que constituíam o Parque foram transformadas em Unidades de Conservação de Uso Sustentável, por meio da instituição do Mosaico de Unidades de Conservação da Serra do Tabuleiro e Terras de Massiambu, composto por uma Unidade de Proteção Integral, o Parque Estadual da Serra do Tabuleiro, e por três de Uso Sustentável: a Área de Proteção Ambiental da Vargem do Braço, a Área de Proteção Ambiental da Vargem do Cedro e a Área de Proteção Ambiental do Entorno Costeiro do Parque Estadual da Serra do Tabuleiro.

O Decreto n. 3.159/2010, que regulamenta e define diretrizes para a implantação da Área de Proteção Ambiental do Entorno Costeiro, criada pela Lei n. 14.661, de 26 de março de 2009, estabelece em seu artigo 22, oito tipos de zonas dentro do município de Palhoça. Cada seção foi caracterizada tendo em vista suas especificidades. A primeira delas é a Zona de Proteção Especial (ZPE), constituída por áreas não edificáveis reservadas à recuperação e proteção ambiental. Abrange Áreas de Preservação Permanente (APPs), remanescentes da Mata Atlântica e vegetações litorâneas do tipo mangue e restinga protetoras de dunas e cordões arenosos, além de áreas identificadas como sítios arqueológicos tombados pelo patrimônio histórico e cultural estadual ou federal. A Zona 2 é de Uso Público e Saneamento (ZPS). É constituída por áreas de domínio público ou privado a serem reservadas para a instalação de equipamentos de interesse público ou social, destinadas ao tratamento de água, efluentes e 
armazenamento e tratamento de resíduos sólidos ou para o desenvolvimento de áreas de lazer e recreação. São passíveis de modificação para servirem à comunidade. A Zona de Uso Sustentável Habitacional (ZUH) é constituída por áreas de domínio público ou privado, reservadas ao desenvolvimento de empreendimentos imobiliários ou turísticos nas modalidades unifamiliar ou multifamiliar. Podem, ainda, receber atividades e serviços comerciais de varejo e outros empreendimentos de pequeno impacto ambiental e que não gerem resíduos perigosos ou efluentes oleosos e químicos não tratáveis em sistema de lodo ativado ou compacto. Foram estabelecidas como Zona de Uso Sustentável Econômico (ZUE), as áreas de domínio público ou privado, reservadas ao desenvolvimento econômico de comunidades rurais e de serviços de apoio à Área de Uso Sustentável Habitacional, a qual deve ser subdividida em uma área rural, onde além da atividade agropecuária podem ser encontrados núcleos de comunidades rurais e áreas de desenvolvimento urbano. Tais áreas são voltadas à instalação de parques de serviços, instalações comerciais, armazéns, equipamentos sociais públicos e privados, shopping centers e hipermercados. Como Zona 5, estabeleceu-se a Zona de Uso Sustentável Industrial (ZUI), constituída por áreas de domínio público ou privado, reservadas à implantação de atividades do setor secundário (transformação e armazéns industriais) e atividades complementares, prioritariamente que envolvam tecnologias limpas, sem a geração de efluentes tóxicos não tratáveis localmente. A Zona de Uso Sustentável Turístico (ZUT) é a zona 6. É constituída por áreas de domínio público ou privado, reservadas à construção de complexos turísticos geradores de renda e emprego, vinculados a medidas compensatórias que possam ser destinadas à recuperação ambiental do seu entorno. Para tentar resolver o problema fundiário, foi criada a Zona de Regularização Habitacional (ZRH), que constitui áreas de domínio público ou privado, identificadas como irregularmente ocupadas ou com índices de ocupação indesejados que demandem medidas de reurbanização para fins de saneamento e proteção ambiental por meio de projetos públicos e/ou privados. Por último, destinou-se uma parte da região para Zona de Captação de Águas (ZCA), destinada ao aproveitamento hídrico (SANTA (ATARINA, 2010). 
Além disso, o Decreto estabeleceu que,

Art. 23. Na definição dos usos permitidos, permissíveis e proibidos de cada uma das zonas, o Plano de Manejo Ambiental, do Município de Palhoça, indicará normas específicas para a Zona de Proteção Especial ZPE e para as Zonas de Uso Público e Saneamento - ZPSs.

Art. 24. O Plano de Manejo de Uso Sustentável estabelecerá critérios relativos ao tamanho do lote, ao índice de aproveitamento, ao número de pavimentos, ao regime volumétrico, à taxa de ocupação, à taxa de impermeabilização, à taxa de arborização, além de outros que forem convenientes. (SANTA CATARINA, 2010)

Passados sete anos da recategorização e do Decreto acima citado, não houve na prática qualquer avanço em relação à solução dos problemas que a legislação objetivava solucionar quando de sua edição. Além disso, mesmo após a lei ser sancionada, os assuntos envolvendo a região, e que são noticiados em periódicos, versam sobre "novos" problemas. Um deles gira em torno da proposta de Plano Diretor do Sul do Município de Palhoça, que prevê para a área a liberação de construções de até quatro pavimentos nas quadras mais próximas ao mar e até 12 andares nas penúltimas quadras antes da Rodovia Evádio Paulo Broering (SC-433). Iniciada a discussão em 2012, ainda não se tem definição de encaminhamentos dessa proposta (JORNAL PALAVRA PALHOCENSE, 2013 p. 6).

Outro problema, que não é novo na região e continua acontecendo, diz respeito ao licenciamento para ligação de energia elétrica. Em setembro de 2013, uma reunião entre FATMA, Prefeito de Palhoça, representantes do órgão municipal do Meio Ambiente de Palhoça, Fundação Cambirela do Meio Ambiente (FCAM) e representantes da CELESC, discutiu a possibilidade dos licenciamentos saírem da esfera estadual e passarem ao município. O argumento é que a FCAM está mais próxima dos cidadãos e por isso poderia facilitar o pedido e a emissão da licença (JORNAL PALAVRA PALHOCENSE, 2013, p.18). O resultado prático da reunião se deu em outubro do mesmo ano, quando um Convênio de Cooperação Técnica e Institucional entre o Estado de Santa Catarina e o município de Palhoça foi firmado. Pelo acordo, com vigência que iria até 31 de dezembro de 2016, a FCAM passaria a ficar responsável pelo licenciamento ambiental na região sul da Baixada do Maciambú, que até então era responsabilidade da FATMA. O Prefeito de Palhoça, Camilo Martins assinalou que estudos preliminares da prefeitura indicam que cerca de $75 \%$ 
das moradias teriam direito às licenças. As outras 25\% não teriam por estarem próximas a leito de rios, dunas ou restingas (JORNAL PALAVRA PALHOCENSE, 2013, p.13).

O problema que parecia, em parte resolvido, retornou em 2016 causando novo embate sobre locais que poderiam ter acesso à energia elétrica e locais sem esse direito. Por trás desse novo episódio está o Ministério Público Federal, que ordenou que a CELESC observasse o Plano Diretor do Município e não promovesse o fornecimento de energia em locais reconhecidos como APP (Áreas de Preservação Permanente). Desse modo, 75 famílias receberam notificação de corte. A nova discussão era se, a partir de 2009, a área era mesmo uma APP ou não (JORNAL PALAVRA PALHOCENSE, 2016, p. 5).

Em março de 2016, ocorreu uma operação que envolveu a FATMA, a Polícia Militar Ambiental (PMA), a CELESC e a Prefeitura de Palhoça e que provocou protesto por parte dos moradores. Na operação, a Prefeitura desapropriou algumas casas construídas irregularmente e a CELESC recolheu cabos de energia ligados de maneira irregular na rede, deixando a população sem luz e sem água, já que a água provém de ponteiras com motor elétrico. Segundo a Polícia Ambiental, houve uma invasão em área do PEST, ocasionando diversos danos ao Meio Ambiente. Toda a operação foi com base na recomendação do Ministério Púbico e no que prevê a legislação. Com isso, mesmo com protestos de moradores, envolvimento do legislativo e executivo municipal, a prefeitura informou que faria reunião com os órgãos competentes para tentar uma solução e que, infelizmente, nada poderia ser feito até que essa reunião fosse realizada (JORNAL PALAVRA PALHOCENSE, 2016, p. 10-11).

Além das questões relacionadas ao licenciamento para liberação de ligação de energia elétrica, áreas que havia tempos foram ocupadas e que com a lei que institui o mosaico estariam liberadas para ocupação, foram questionadas pelo Ministério Público Federal (MPF). O autor da ação civil pública, Walmor Alves Moreira, questionou as edificações que, segundo o MPF, foram erguidas em APP. "A presente demanda visa à condenação dos réus a fazerem cessar ocupação danosa em terras de marinha caracterizadas como área de preservação permanente" (JORNAL PALAVRA PALHOCENSE 2015, p. 8). O caso está tramitando na $6^{a}$ Vara Federal e, se condenados, os réus da ação (município de Palhoça, FCAM e FATMA) deverão recuperar o meio ambiente degradado a 
partir de um programa aprovado pelo MPF. Além disso, a Prefeitura de Palhoça precisará promover a realocação da população de baixa renda para outras áreas.

A área questionada é apresentada na figura 4.

Figura 4: Área questionada pelo Ministério Público Federal

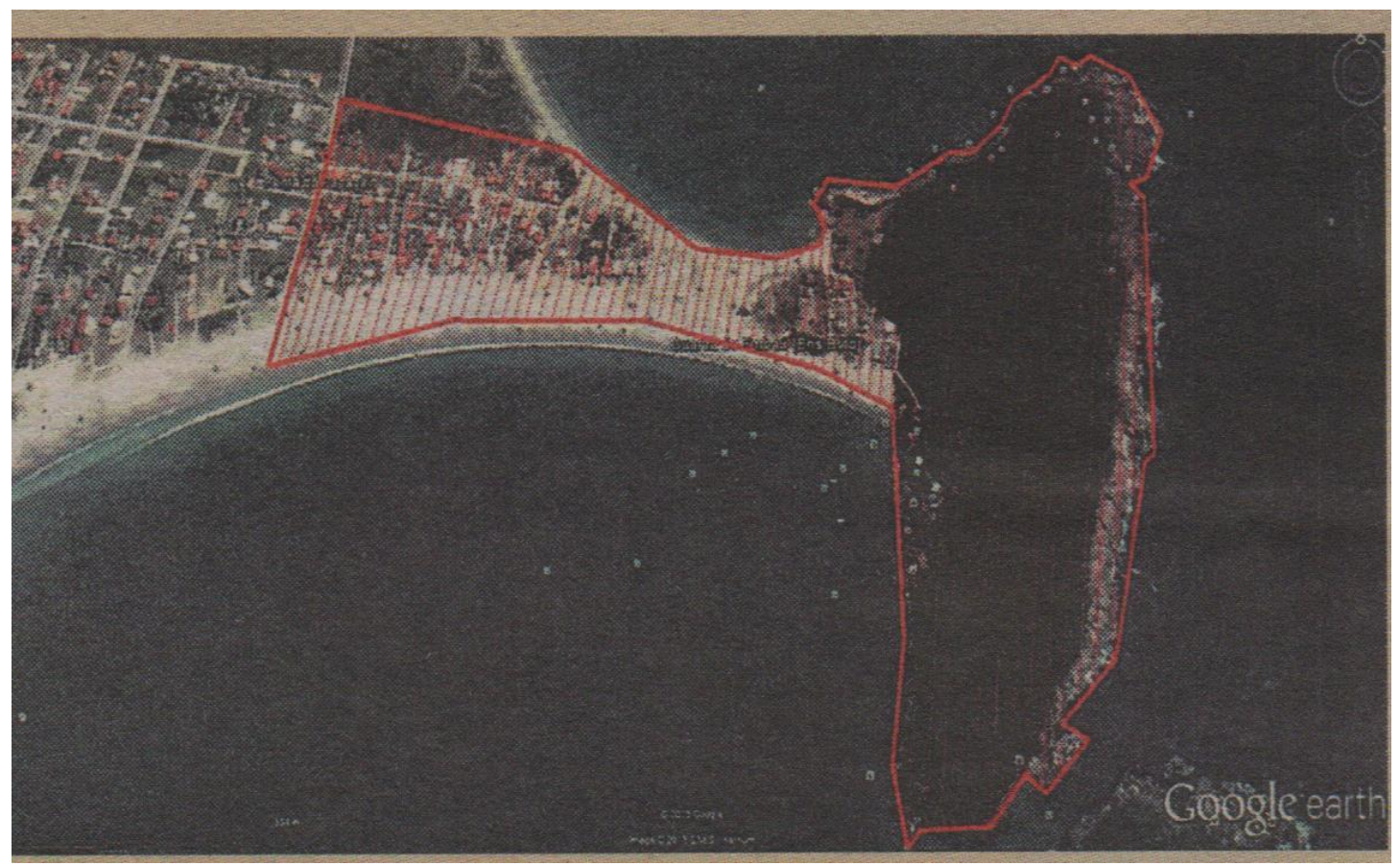

Fonte: PALAVRA PALHOCENCE 04/2015, p. 08

Na mesma linha de entendimento, o MPF ajuizou ações civis públicas pedindo providências para áreas da Pinheira e Guarda do Embaú. Na Pinheira, o objeto versa sobre áreas ocupadas entre a Pinheira e Praia de Cima, com exceção dos ranchos de pesca que são pouquíssimos, por sinal. Em área de marinha, em cima de dunas e restingas, várias edificações se proliferam, causando danos irreversíveis à natureza. Já na Guarda do Embaú, a ação questiona ações às margens do Rio Embaú, solicitando ao município identificar, desfazer e lacrar ligações clandestinas de esgoto (JORNAL PALAVRA PALHOCENSE, 2015, p. 30).

Em meio a tantos questionamentos, tantos conflitos em uma região tão frágil ambientalmente, quando se pensava na resolução desses problemas a partir da lei do mosaico, eis que toda a movimentação em torno do projeto de recategorização e da própria lei estão em xeque. Isso porque a Procuradoria Geral da República (PGR) 
protocolou no Supremo Tribunal Federal (STF) uma Ação Direta de Inconstitucionalidade (ADI), questionando a Lei Estadual n. 14.661, de 2009 (DIÁRIO CATARINENSE, 2015, p. 6). Segunda a ADI, a lei de 2009 contraria a Constituição Federal e o SNUC. A ADI, assinada por Rodrigo Janot, também acrescenta que a lei do Estado nega os compromissos assumidos pelo Brasil com a proteção dos recursos naturais e da biodiversidade, colocando em risco importantes ecossistemas de seu território. Além de tentar reverter a aprovação da lei, a ação pede a sua suspensão imediata e cobra informações da ALESC e do governo do Estado. O problema levantado retorna à época de discussão do projeto, que não levou em conta o trabalho científico realizado pela STCP Engenharia de Projetos, que sugeria uma saída diferente para a redefinição do Parque. Ainda de acordo com a lei de 2009, a área ganharia um plano de manejo, que até então não existe.

\section{Considerações finais}

Em novembro de 2015, o PEST completou 40 anos. Uma série de reportagens foi publicada pelo Jornal Diário Catarinense trazendo aspectos positivos e o papel indispensável do PEST para o equilíbrio ambiental de Santa Catarina. As reportagens também abordam os aspectos que emperram a implantação definitiva da UC. Entre esses aspectos, a falta do Plano de Manejo, que em 2009 foi previsto para ficar pronto em cinco anos. Para o periódico, trata-se de "uma espécie de constituição para preservar a natureza: assim é o plano de manejo, uma lei que estabelece restrições e deveres para reservas que precisam ser preservadas" (DIÁRIO CATARINENSE, 2015, p. 6). Desse modo, podemos afirmar que a recategorização não foi a solução para os problemas de implantação do PEST na Baixada do Maciambú.

Em meio a tantos impasses e incertezas, os moradores que estavam na Baixada do Maciambú antes mesmo que se pensasse em Parque Estadual da Serra do Tabuleiro, seguem suas vidas. Possivelmente, acreditam que a vida no local hoje está melhor do que há 40 anos, dando-nos a impressão de que vivem alheios a tantas questões legais que ainda estão em aberto. As mudanças em suas vidas não podem ser relacionadas apenas ao Parque. Foram seguindo o curso do "progresso". 
A participação direta do PEST na vida dos moradores da Baixada do Maciambú se deu pela valorização da natureza, já que na percepção da população, sem o Parque, a região estaria invadida desordenadamente e que, além disso, eles dependem diretamente da conservação do meio ambiente. A natureza também segue se transformando e sendo transformada, à mercê da criação de leis que busquem um entendimento maior e o equilíbrio entre o Meio Ambiente e a sustentabilidade da região.

\section{Referências}

BRASIL. Lei $\mathbf{n}^{\circ}$ 4.771, de 15 de setembro de 1965. Institui o novo Código Florestal Brasileiro. Brasília. Disponível em: http://www.planalto.gov.br/ccivil_03/leis/L4771.htm. Acesso em: 14 jul. 2015.

CABRAL, Luiz Otávio. Assessor da Comissão de Turismo e Meio Ambiente/ALESC. Memória das ações do Fórum Parlamentar do Parque Estadual da Serra do Tabuleiro. Florianópolis, ALESC, [S.d.].

DANTAS, Rafael. FCam passa a emitir licenciamento ambiental na para a região sul. JORNAL PALAVRA PALHOCENSE, $\mathrm{n}^{\circ}$ 405, 10 de outubro de 2013.

DANTAS, Rafael. Plano diretor do sul do município continua parado na câmara. JORNAL PALAVRA PALHOCENSE, $n^{\circ}$ 389, 06 de junho de 2013.

DEAN, Warren. Aferro e fogo: a história da devastação da Mata Atlântica Brasileira. São Paulo: Companhia das Letras, 1996.

DRUMMOND, José Augusto. A história ambiental: temas, fontes e linhas de pesquisa. Estudos Históricos, Rio de Janeiro, v. 4, n.8, 1991, p. 177-197.

DRUMMOND, José Augusto. Devastação e preservação ambiental: os parques nacionais do estado do Rio de Janeiro. Niterói: EDUFF, 1997.

FATMA. Parque Estadual da Serra do Tabuleiro: retratos da fauna e flora. Florianópolis: CriAg, 2009. 
FORTKAMP, Cristiane. Parque Estadual da Serra do Tabuleiro (PEST): história e conflito sócio-ambiental (1975-2007). Dissertação (Mestrado em História) - Universidade Federal de Santa Catarina. Florianópolis, 2008.117 f.

FRANCO, José Luiz de Andrade; DRUMMOND, José Augusto. História das preocupações com o mundo natural no Brasil: da proteção a natureza à conservação da biodiversidade. In: FRANCO, José Luiz de Andrade; DRUMMOND, José Augusto; SILVA, Sandro Dutra; TAVARES, Giovana Galvão. História Ambiental: fronteiras, recursos naturais e conservação da natureza. Rio de Janeiro: Garamond, 2012, p. 333-366.

GOOGLE. Baixada do Maciambú. Disponível em: https://www.google.com.br/maps/search/baixada+do+maciambu/@-27.85632,48.6482775,10548m/data=!3m1!1e3. Acesso em: 10 de Nov. 2015.

IRIS, Isonyane. Sem luz e sem água. JORNAL PALAVRA PALHOCENSE, n 530, 24 de março de 2016, p. 10-11.

MACHADO, Mariana de Medeiros. Uso e ocupação do solo da Área de Proteção Ambiental do Entorno Costeiro do Parque Estadual da Serra do Tabuleiro: contexto para a praia da Pinheira e Guarda do Embaú, no município de Palhoça/SC. Dissertação (Mestrado em Engenharia Ambiental)-Universidade Federal de Santa Catarina, Florianópolis, 2014, 191 p.

Mapa dos Biomas e Vegetação. Disponível em: https://ww2.ibge.gov.br/home/presidencia/noticias/21052004biomashtml.shtm. Acesso em: 22 ago. 2015.

MORETTO, Samira Peruchi; CARVALHO, Miguel Mundstock Xavier de; NODARI, Eunice Sueli. A legislação ambiental e as práticas de reflorestamento em Santa Catarina. In: Encontro Nacional da Annpas, 5, 2010. Anais eletrônicos [...].Florianópolis: [S.I.], 2010. Disponível em: www.anppas.org.br/encontro5/cd/artigos/Gt16-55-26-20100831195920.pdf. Acesso: 11 nov. 2015.

PÁDUA, José Augusto. Um sopro de destruição: pensamento político e crítica ambiental no Brasil escravista, 1786-1888. 2. ed. Rio de Janeiro: Jorge Zahar Ed, 2004.

PERES, Jackson Alexsandro Peres. Parque Estadual da Serra do Tabuleiro: natureza, legislação e conflitos na Baixada do Maciambú - Palhoça/SC (1975-2012). Tese (Doutorado em História) - Universidade Federal de Santa Catarina, Florianópolis, 2017, 316 p.

POTTER, Hyury. Demarcação é contestada. DIÁRIO CATARINENSE, Florianópolis 24 set. 2015, p. 6. 
POTTER, Hyury. Sem Manejo. DIÁRIO CATARINENSE, Florianópolis, 09 nov. 2015, p. 6.

PROJETO DE PROTEÇÃO DA MATA ATLÂNTICA EM SANTA CATARINA. Delimitação e planejamento de demarcação do Parque Estadual da Serra do Tabuleiro: diagnóstico socioeconômico e Ambiental. RELATÓRIO FINAL 03FAT0206R01. Curitiba, 2008.

S/A. Comissão quer criar APA da Baixada do Maciambú. ESPINHEIRA, nº 111, agosto de 2005.

S/A. Demarcação do Parque será definida só ano que vem. ESPINHEIRA, $n^{\circ} 129$, dezembro de 2007.

S/A. Diminuem restrições em áreas adjacentes ao Parque. ESPINHEIRA, $n^{\circ} 122$, setembro de 2006.

S/A. JORNAL DA RECATEGORIZAÇÃO, n. 1, 11 de fevereiro de 2009.

S/A. Ministério Púbico Federal agora volta as atenções para a Pinheira e a Guarda do Embaú. JORNAL PALAVRA PALHOCENSE, n 504, 17 de setembro de 2015, p. 30.

S/A. Projeto é considerado inviável. ESPINHEIRA, n 118, abril de 2006.

SANTA CATARINA. Decreto n 1.260 de 1 de novembro de 1975. Cria o Parque Estadual da Serra do Tabuleiro. Disponível em:

http://www.mp.sc.gov.br/legisla/est_leidec/decreto/1938_1989/de1260_75.htm. Acesso em: 1 de set. de 2012.

SANTA CATARINA. Decreto n $^{\circ} 3.159$ de 24 de março de 2010. Regulamenta e define diretrizes para a implantação da Área de Proteção Ambiental do Entorno Costeiro, criada pela Lei no 14.661, de 26 de março de 2009. Disponível em:

http://server03.pge.sc.gov.br/LegislacaoEstadual/2010/003159-005-0-2010-003.htm. Acesso em: 27 set. 2015.

SANTA CATARINA. Lei $\mathbf{n}^{\circ} \mathbf{1 4} .661$ de 2009. Reavalia e define os atuais limites do Parque Estadual da Serra do Tabuleiro, criado pelo decreto $n^{\circ} 1.260$, de $1^{\circ}$ de novembro de 1975 , e retificado pelo decreto $n^{\circ} 17.720$, de 25 de agosto de 1982 , institui o mosaico de unidades de conservação da serra do tabuleiro e terras de massiambu, cria o fundo especial de regularização, implementação e manutenção do mosaico - feuc, e adota outras providências. Disponível em: http://leisestaduais.com.br/sc/lei-ordinaria-n-14661-2009santa-catarina-reavalia-e-define-os-atuais-limites-do-parque-estadual-da-serra-dotabuleiro-criado-pelo-decreto-n-1260-de-1-de-novembro-de-1975-e-retificado-pelo-decreton-17-720-de-25-de-agosto-de-1982-institui-o-mosaico-de-unidades-de-conservacao-da-serra- 
do-tabuleiro-e-terras-de-massiambu-cria-o-fundo-especial-de-regularizacao-

implementacao-e-manutencao-do-mosaico-feuc-e-adota-outras-providencias. Acesso em: 07 dez. 2016.

SILVA, João José da. Moradores com medo de cortes de luz no sul. JORNAL PALAVRA PALHOCENSE, $\mathrm{n}^{\circ}$ 522, 28 de janeiro de 2016.

SILVA, João José da. MPF questiona ocupação da Ponta do Papagaio. JORNAL PALAVRA PALHOCENSE, $n^{\circ}$ 482, 16 de abril de 2015.

SILVA, João José da. Prefeitura de Palhoça quer licença para ligação de energia na Baixada do Maciambú. JORNAL PALAVRA PALHOCENSE, n 400, 09 de setembro de 2013. 